\title{
O CHECKPOINT DE NGE LAY E A URGÊNCIA DE FALAR DE NOSSAS VULVAS
}

NGE LAY'S CHECKPOINT AND THE URGENCY TO TALK ABOUT OUR VULVAS

\section{EL CHECKPOINT DE NGE LAY Y LA URGENCIA DE HABLAR SOBRE NUESTRAS} VULVAS

\author{
Maria Cristina Simões Viviani ${ }^{1}$ \\ do) $10.21665 / 2318-3888 . v 8 n 15 p 36-67$
}

\begin{abstract}
RESUMO
Partindo da obra "Checkpoint" da artista birmanesa Nge Lay, este artigo tem o objetivo de abordar discussões sobre a construção cultural da vulva através da arte. Com base em uma perspectiva feminista e decolonial, cito obras que trazem a vulva como elemento central, e fazem emergir discussões acerca de seu simbolismo na contemporaneidade. Diante do padrão de corpos imposto, houve uma desnaturalização daqueles que não correspondiam ao colocado pela mídia para consumo, induzindo a um descontentamento das mulheres com sua realidade. Com isso, há uma necessidade culturalmente fabricada para a cirurgia plástica íntima, produzida como justificativa de um consumo de corpos feita por um sistema de regulação da feminilidade e do que significa ser mulher. Assim, através de trabalhos de diferentes artistas, busco trazer as pautas que atravessam a estética padronizada da anatomia feminina e que de alguma forma questionam narrativas hegemônicas. Por fim, a pesquisa tem como objetivo de que através da compreensão das disputas acerca do corpo da mulher, e de um maior repertório de imagens e representações, se democratize o entendimento de beleza de forma mais diversa e representativa.
\end{abstract}

Palavras-chave: Vulva. Arte. Mianmar. Feminismo. Decolonialidade.

\footnotetext{
${ }^{1}$ Doutoranda em Antropologia pela Universidade Federal do Pará, tem como área de pesquisa arte, gênero e decolonialidade. Possui mestrado em Antropologia pela Universidade Federal de Sergipe. Cursou bacharelado e licenciatura em Educação Física pela Universidade Estadual de São Paulo. E-mail para contato: mcris.vivi@gmail.com.
} 


\begin{abstract}
Based on the work "Checkpoint" by Burmese artist Nge Lay, this article aims to discuss art's cultural construction of the vulva. From a feminist and decolonial perspective, I bring attention to works that bring the vulva as a central element and stir discussions about its symbolism in contemporary times. In view of the imposed standard of bodies, there was a denaturalization of those who do not correspond to what was dispersed by the media, which led to women's despondency with their reality. Thus, there is a culturally manufactured need for intimate plastic surgery, justified by a consumption of bodies invented by a system that regulates femininity and what it means to be a woman. Through the work of different artists, I seek guidelines that go against the standardized aesthetics of female anatomy and that, somehow, bring into question hegemonic narratives. Finally, the research has the objective of understanding the disputes about women's bodies, and how a greater repertoire of images and representation can deliver an understanding of beauty that may be democratized in a way that is more diverse and representative.
\end{abstract}

Keywords: Vulva. Art. Myanmar. Feminism. Decoloniality.

\title{
RESUMEN
}

Basado en el trabajo "Checkpoint" de la artista birmana Nge Lay, este artículo tiene como objetivo abordar las discusiones sobre la construcción cultural de la vulva a través del arte. Basado en una perspectiva feminista y decolonial, menciono obras que traen la vulva como un elemento central, y traen discusiones sobre su simbolismo en los tiempos contemporáneos. En vista del estándar de los cuerpos impuestos, hubo una desnaturalización de aquellos que no correspondían con los puestos por los medios de comunicación para el consumo, lo que provocó un descontento entre las mujeres con su realidad. Con esto, existe una necesidad culturalmente fabricada de cirugía plástica íntima, producida como una justificación para el consumo de cuerpos fabricados por un sistema de regulación de la feminidad y lo que significa ser mujer. Por lo tanto, a través del trabajo de diferentes artistas, busco traer las pautas que cruzan la estética estandarizada de la anatomía femenina y que de alguna manera cuestionan las narrativas hegemónicas. Finalmente, la investigación tiene el objetivo de que a través de la comprensión de las disputas sobre el cuerpo de la mujer y un mayor repertorio de imágenes y representaciones, la comprensión de la belleza se democratizará de una manera más diversa y representativa.

Palabras clave: Vulva. Arte. Myanmar Feminismo. Decolonialidad. 


\section{Introdução}

A vulva é historicamente foco de disputa de diferentes narrativas, sejam elas religiosas, médicas, sejam midiáticas. Aqui pretendo abordar algumas dessas disputas usando a arte como fio condutor. A partir de uma perspectiva feminista e decolonial, trago diferentes obras e contextos que tratam da vulva e fazem emergir diversas discussões acerca de seu simbolismo na contemporaneidade. A arte vem abordando a temática feminina principalmente através de artistas mulheres que ocupam cada vez mais os espaços que antes eram privilegiadamente masculinos. Assim, é também através da arte que o corpo da mulher vem sendo ressignificado. Referida enquanto portal de nascimento do ser humano, fonte de prazer, ou local de silenciamento, a imagem da vulva no meio artístico perpassa por sua anatomia, sua estética, sua expressão da sexualidade feminina, entre outros, sendo objeto relevante de pesquisa e debate.

Em 2018, em uma viagem à Tailândia, me deparei com o trabalho da birmanesa Nge Lay no Centro de Arte e Cultura de Bangkok. Uma vulva de tecido de grandes dimensões pendurada em um dos salões do museu era exposta em conjunto com um fino colchão no chão e um vídeo. Sua obra fazia parte da Bienal de Arte de Bangkok e estava em exibição no segundo semestre daquele ano. A obra me despertou interesse e logo a relacionei com leituras feministas e decoloniais acadêmicas, percebendo como as questões sobre ser mulher encontram suas intersecções mesmo em realidades e contextos tão distintos.

A artista nascida em um dos países vizinhos à Tailândia, Mianmar, traz em seu trabalho chamado "Checkpoint" (fig. 1) questões ligadas ao gênero. Bacharela em Arte e Cultura pela Universidade de Yangon, a artista teceu uma vulva feita com dimensão suficiente para ser atravessada por um adulto. Essa vulva, pendurada na vertical nos museus onde é exibida, é uma obra de interação em que o visitante pode perpassá-la, assim como uma porta. Não à toa, o nome "Checkpoint" remete a uma passagem obrigatória, em que o indivíduo deve se identificar. A artista usa a expressão em língua inglesa para se referir ao momento do parto, em que todo ser humano, independentemente do sexo, passaria pela vagina. Com o seu trabalho, Lay nos lembra, nas palavras dela, que "todos 
nós passamos por esse portão para chegarmos aqui ${ }^{2 \prime}$. A artista ainda acrescenta que gostaria que as pessoas passassem pelo seu trabalho como um portão, percebendo que é a partir daquele lugar, a vagina de uma mulher, onde se inicia a vida humana.

Figura 1 - Instalação Checkpoint de Nge Lay, Bienal de Arte de Bangkok, 2018.

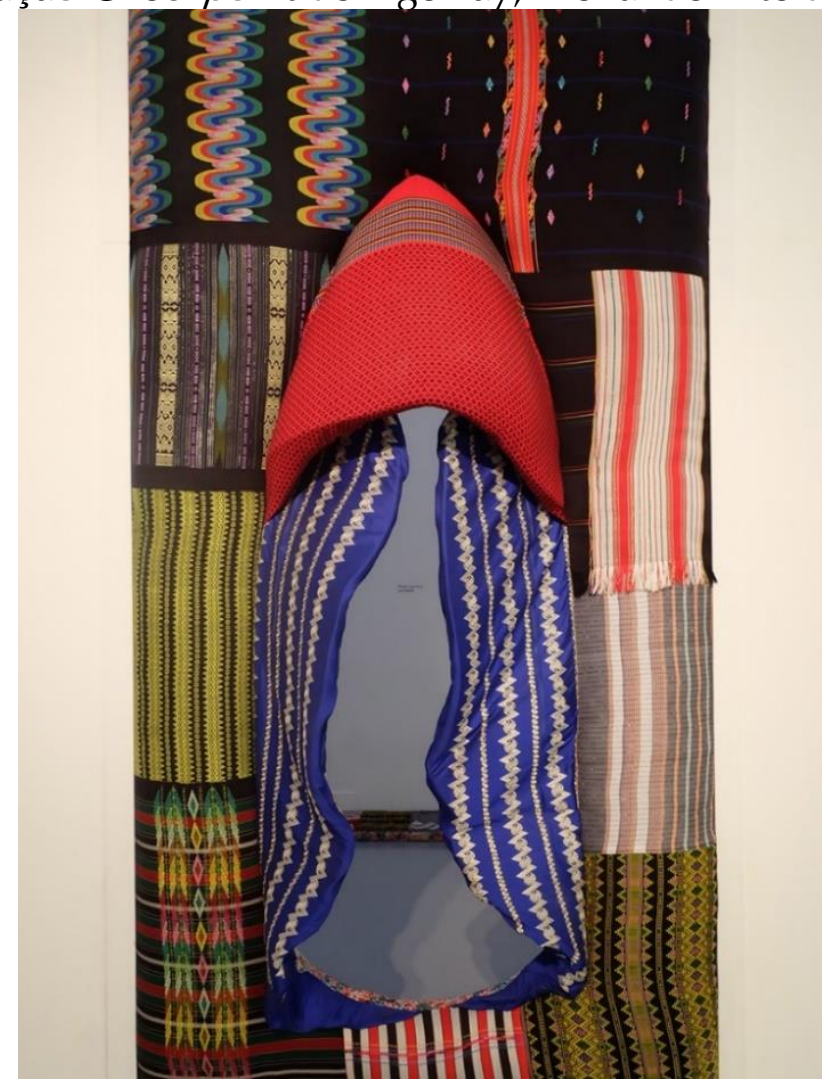

Fonte: Nge Lay's Checkpoint, 2018.

O trabalho de Nge Lay abre um importante debate sobre a condição de ser mulher na sociedade atual, especificamente em Mianmar. Apresentar uma vulva gigante como obra de arte em uma sociedade pautada em sua construção na hierarquização dos gêneros, rompe com expectativas patriarcais e abre fissuras para recolocar a mulher e a relação com a sua sexualidade na sociedade. É usando o trabalho de Lay como ponto de partida que pretendo abordar obras que utilizam a vulva em sua simbologia para tratar de

2 Todas as citações de Nge Lay foram retiradas de entrevistas dadas para canais de arte e cultura internacionais. A tradução é livre da autora. 
questões de gênero que aflingem as mulheres.

Assim, através de trabalhos de diferentes artistas, busco trazer as pautas que atravessam a estética padronizada da anatomia feminina e que de alguma forma questionam narrativas hegemônicas. As obras aqui referenciadas foram encontradas em busca online, com exceção da obra de Nge Lay, que inicia a ideia da pesquisa, e da artista paraense Lise Lobato, a qual tive a oportunidade de ver seu trabalho pessoalmente. $\mathrm{O}$ restante dos artistas foi referenciado por artigos acadêmicos ou jornalísticos lidos durante a pesquisa para a base do texto. As principais palavras utilizadas nos sites de busca Google, Google Acadêmico e Scielo foram "artista", "arte", "vulva", "vagina" e suas variáveis tanto em português quanto em espanhol e inglês. Com base nos resultados e nas obras citadas por outros autores, busquei mais informações a respeito do artista e análises de curadores sobre o seu trabalho para interpretar se a obra poderia acrescentar a esta investigação. Nas obras escolhidas para serem mencionadas nesta pesquisa, me ative à princípio nas leituras curatoriais para em seguida traçar seu paralelo com o conceito a ser relacionado para o aprofundamento e continuidade da reflexão do estudo. Assim, buscando esclarecer o impacto da obra em seu contexto de origem.

O desenvolvimento do artigo está organizado por subtítulos que trazem o tema principal a ser tratado e os artistas escolhidos para subsidiar a discussão proposta. Com isso, espera-se que o leitor se situe na narrativa desenvolvida a fim de alcançar o propósito desta pesquisa. Em suma, esta análise tem como objetivo que, através da compreensão das disputas acerca do corpo da mulher, e de um maior repertório de imagens e representações, se democratize o entendimento de beleza de forma mais diversa e representativa.

\section{Desigualdade de gênero no mundo e na arte - Georgia O'Keeffe}

A fim de contextualizar minimamente o processo histórico e geográfico do país de origem de Nge Lay, faço algumas comparações de Mianmar, antiga Birmânia, com o Brasil. Mesmo os dois países sendo muito distantes no globo, existem pontos de convergência entre eles. Ambos possuem passados de colonização e dizimação de 
diversos grupos étnicos originários nos países. Cada qual com suas particularidades, Brasil sendo colonizado pelos portugueses, enquanto Mianmar, assim como sua vizinha Índia, colonizada pelos britânicos. Porém a extensão territorial, de fato, é muito distinta. A área brasileira é 12 vezes maior do que a área geográfica birmanesa, sendo a população apenas três vezes maior do que a do país do sudeste asiático.

Em 2019, segundo o relatório mundial de Desenvolvimento Humano (IDH) divulgado pelo Programa das Nações Unidas para o Desenvolvimento (Pnud), os birmaneses ocupavam na 145 a posição, sendo qualificado como um país de médio desenvolvimento humano, enquanto o Brasil ficou na 79a posição, entre os países de alto desenvolvimento humano. Lembrando que as qualificações do IDH são de muito alto, alto, médio e baixo, com 189 países no ranking.

No que se diz especificamente à mulher e às políticas de gênero, Mianmar parece ter maiores problemas em comparação ao Brasil, segundo o Índice de Desigualdade de Gênero publicado em 2019, apesar dos dois países possuírem legislação direta para punição em casos de violência contra a mulher. O Índice de Desigualdade de Gênero é uma medida que reflete a desigualdade entre homens e mulheres em três dimensões diferentes: saúde reprodutiva (taxa de mortalidade materna e taxa de gravidez de adolescentes), empoderamento (parcela de cadeiras parlamentares ocupadas por mulheres e parcela da população com pelo menos algum ensino médio) e participação no mercado de trabalho (taxa de participação na força de trabalho). No último relatório realizado em 2018, o Brasil se encontrava na 89ª posição, enquanto Mianmar estava na $106^{\mathrm{a}}$, demonstrando ter maiores problemas sociais relacionados à gênero segundo o índice. Mesmo com o distanciamento dos 17 países entre a colocação do Brasil e Mianmar, mulheres apresentam problemas típicos de sociedades patriarcais em maior ou menor intensidade.

A problemática da desigualdade de gênero encontrada em diferentes escalas em diversos países não se expressa somente nos números formais governamentais, como também se reflete na arte. No conhecido texto de Linda Nochlin "Why Have There Been No Great Women Artists?", a autora comenta o status da mulher na arte ao longo dos séculos. A autora conclui, em seu ensaio, que as raras oportunidades permitidas para as mulheres 
na área artística não possibilitavam que elas chegassem ao mesmo nível técnico e de influência na arte como os homens. Assim, Nochlin desconstrói uma percepção histórica machista, em que a genialidade artística seria reservada exclusivamente aos homens. Apontando para a diferença no tratamento dos sexos nas instituições, a autora demonstra como a própria estrutura construída para a legitimação do mercado da arte impossibilitava mulheres de acessarem espaços privilegiados destinados aos jovens artistas.

Nachlin acrescenta de que o assombro deve ficar por parte das mulheres que, mesmo com toda a ausência de apoio, conseguiram se destacar ao longo da história. Mas há um recorte claro dessas mulheres que tiveram a atípica oportunidade de exercerem a arte enquanto profissão:

Mas, na realidade, como sabemos, nas artes e em centenas de outras áreas, as
coisas permanecem estultificantes, opressivas e desanimadoras para todos
aqueles - mulheres incluídas - que não tiveram a sorte de nascer brancos, de
preferência da classe média e, acima de tudo, homens. A fallha não está em
nosso horóscopo, nossos hormônios, nossos ciclos menstruais ou nossos
espaços internos vazios, mas em nossas instituições e nossa educação -
educação que inclui tudo o que acontece conosco desde o momento em que
entramos, neste mundo de símbolos, sinais e significados. De fato, o milagre é
que, dadas as enormes probabilidades contra mulheres ou negros, muitos
conseguiram alcançar tanta excelência - senão grandeza imponente - naqueles
bastões de prerrogativas masculinas brancas como ciência, política ou arte.
(NOCHLIN, 2006, p. 5 , tradução minha). Assim, a grande maioria das mulheres que conseguiu conquistar território no campo elitizado das artes era branca, vinha de classes econômicas privilegiadas, e tinha homens como tutores. Georgia O'Keeffe, pintora estadunidense, reconhecida por suas pinturas de flores e por seu abstracionismo, tinha o seu sucesso constantemente relacionado ao seu marido, o fotógrafo Alfred Stieglitz. Muitas de suas pinturas da década de 1920 foram relacionadas à anatomia feminina, porém sob forte negação da artista. A artista decidiu se distanciar do abstracionismo para não ser novamente mal interpretada, e queria deixar claro que sua intenção em suas obras era a de ser objetiva. Suas pinturas, ela reestabelecia, são apenas flores, apesar dos críticos julgarem similaridade com vulvas. Mesmo assim, nos anos 1970 o movimento feminista abordou algumas de suas pinturas como sinal de empoderamento feminino, ainda que a autora recusasse a relação (DROHOJOWSKA-PHILP, 2004). 
Embora O'Keeffe estivesse ansiosa para encontrar revisores que não apresentassem sensualidade, feminilidade ou Freud, suas tentativas de manipular a recepção crítica não tiveram êxito. Na maioria dos casos, a pintura de O'Keefe foi revisada ao lado das fotografias de Stieglitz. Como sempre, Stieglitz e seu trabalho foram descritos em termos reverenciais, e vários escritores continuaram a creditá-lo como a força por trás da carreira de O'Keeffe. Embora suas fotografias, além dos retratos de O'Keefe, fossem analisadas formalmente, suas pinturas foram discutidas em grande parte como expressão do seu gênero. (DROHOJOWSKA-PHILP, 2004, p. 229, tradução minha).

Figura 2 - Três diferentes obras de Georgia O'Keeffe. Da esquerda para a direita: Black Iris, 1926. Óleo sobre tela, 91,4 x 75,9 cm. Grey Lines with Black, Blue and Yellow, 1923. Óleo sobre tela, $121.9 \times 76.2 \mathrm{~cm}$. Grey Line with Lavender and Yellow, 1923. Óleo sobre tela, $121.9 \times 76.2 \mathrm{~cm}$.
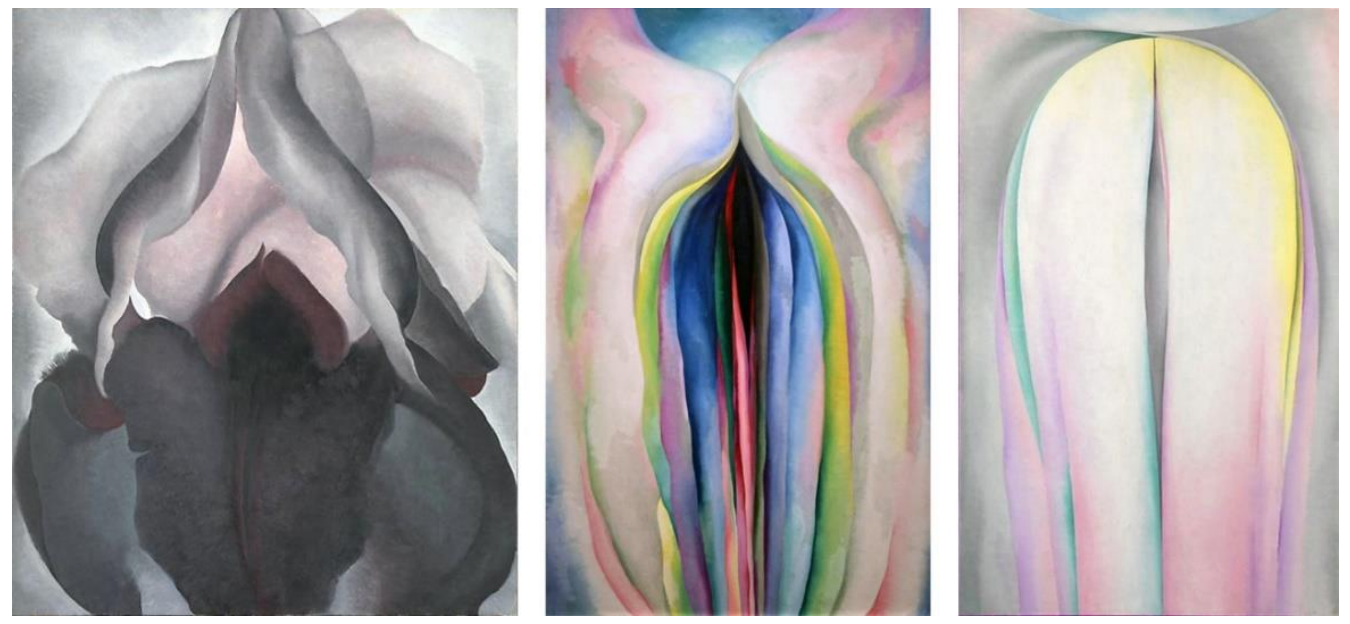

Fonte: DABROWSKI, 2011.

Enquanto $\mathrm{O}^{\prime}$ Keeffe não tinha o intuito de fazer referência à vulva, Lay deixou clara sua intenção em "Checkpoint". As obras, separadas por quase um século, remetem a polêmicas em torno da genitália feminina, intencionalmente ou não. O referencial do material utilizado pela birmanesa em seu trabalho faz alusão direta às saias tradicionais vestidas diariamente pelas mulheres birmanesas, os longyi. Lay costura oito tipos de longyi de diferentes grupos étnicos do país. A escolha do material é interessante por se tratar de uma vestimenta tradicional, porém usada rotineiramente ainda no presente. Tanto mulheres quanto homens birmaneses usam longyi em seu cotidiano, porém o 
estilo das saias é diferente. Enquanto a das mulheres existe uma fita de amarração na cintura, os homens apenas dão um nó no próprio tecido para amarrá-la. O comprimento da saia é na altura dos tornozelos, independente do sexo, mas suas estampas variam das femininas para as masculinas. As das mulheres costumam ter temas florais e cores mais vibrantes, enquanto as dos homens são geralmente padrões de xadrez ou listras em cores mais escuras. É comum ver homens e mulheres com trajes sociais típicos ocidentais cobrindo o dorso em simultâneo à vestimenta tradicional local sobre as pernas.

Há a possibilidade de leitura e interpretação dos tecidos de longys utilizados na obra de Nge Lay por aqueles que os reconhecem e os percebem enquanto elemento simbólico em seu trabalho. Ranciére (2005), quando discursa sobre a "Partilha do Sensível", em que aborda a forma em que as estéticas são possíveis de serem compartilhadas, percebe como as obras artísticas podem ter impacto social quando seus códigos são a partir de um comum. Com isso, a arte atinge o público a partir de uma sensibilidade partilhada coletivamente. A escolha da artista pelos longyi femininos para a representação da vulva em seu trabalho pode ser considerada como uma forma de representatividade e empoderamento das birmanesas. É como se agisse na forma de uma denúncia, de uma cultura de silenciamento das mulheres ratificada pela vergonha de sua própria anatomia, e um pedido, para que não se calem mais.

"Checkpoint" levanta questionamentos sobre o local da mulher na sociedade e a relação da mulher com seu próprio corpo, especificamente a área genital. Lay comenta que o seu trabalho é uma obra consequente da "combinação de diferentes sentimentos, satisfação e insatisfação, orgulho e tristeza que advém de ser mulher ${ }^{3 \prime}$. A artista complementa que o interesse com seu trabalho é de "enviar uma mensagem de que a porta pela qual nascemos para o mundo não deve ser considerada impura ${ }^{4 \prime}$.

3 Entrevista concedida à Yavuz Gallery, 2018, tradução minha.

4 Entrevista concedida à Yavuz Gallery, 2018, tradução minha. 
Figura 3 - Instalação Checkpoint de Nge Lay, Bienal de Arte de Bangkok, 2018. Dimensões variadas.

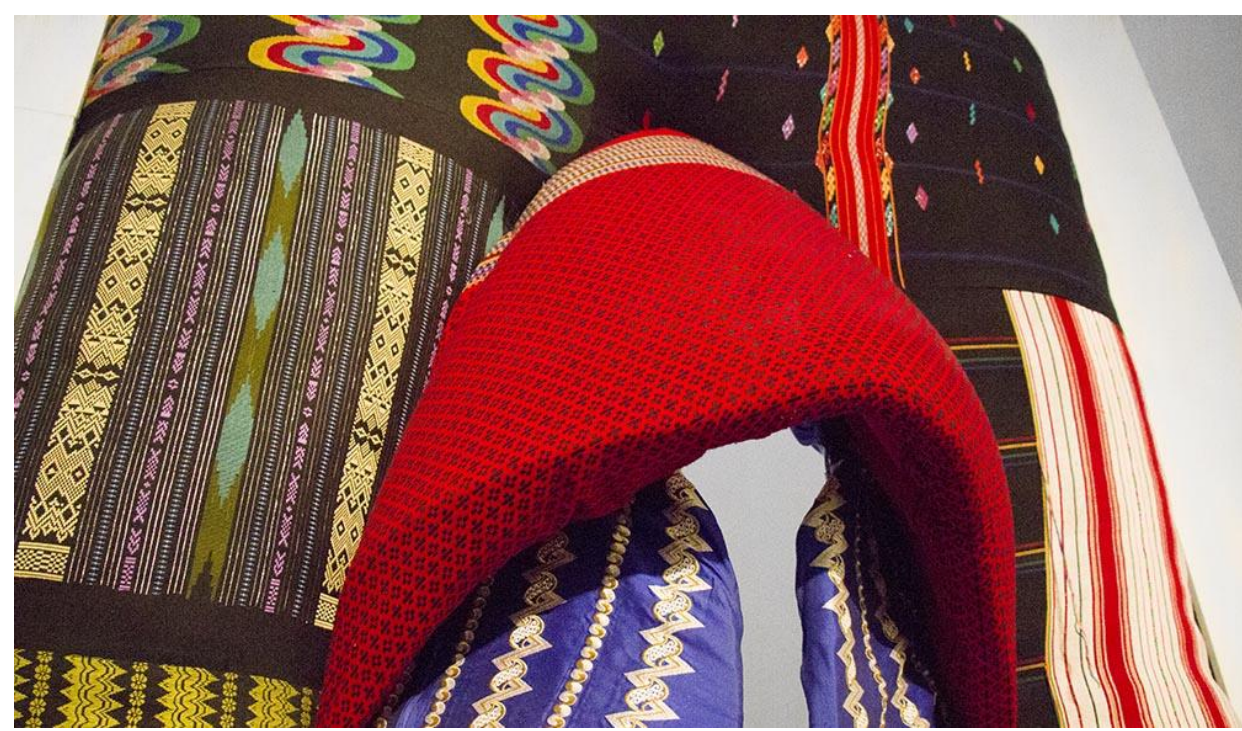

Fonte: Nge Lay's Checkpoint, 2018.

No livro de Emily Martin (2006), "A Mulher no Corpo - uma análise cultural da produção", a autora demonstra a construção cultural do conhecimento científico sobre o corpo da mulher. Martin argumenta que as expectativas culturais haviam induzido a erros nas descrições de observações científicas renomadas. A partir deste ponto, a antropóloga demonstra como imagens que são culturalmente influenciadas na biologia são sexistas, demonstrando como os corpos das mulheres e dos homens estão inevitavelmente enredados nas operações de poder.

A "impureza" com que é tratado o órgão feminino é frequentemente relacionada ao desconhecimento de que se tinha sobre o corpo da mulher e aos mecanismos fisiológicos do ciclo menstrual. Com uma medicina escrita por homens, é por eles mesmos que a fisiologia feminina foi estudada e exposta ao longo dos anos. Com ignorância sobre a genitália da mulher, os homens retrataram a menstruação tantas vezes como "impura", a estigmatizando não só para a sociedade masculina, mas para a feminina também. As raízes desse conhecimento gerado apenas por homens têm consequências marcantes ainda hoje, quando as próprias mulheres acreditam que sua fisiologia e fisionomia são passivas de vergonha (Martin, 2006). 
Beauvoir (1980), ao explicar as mulheres como o "segundo sexo" da nossa sociedade, expõe as consequências desse saber insistentemente construído por homens, colocando as mulheres como um corpo estranho, um corpo segundo a ser representado. Esse processo histórico, ainda que não seja linear e que tenha tido suas resistências ao longo do caminho, deixou marcas profundas no entendimento das mulheres com o seu próprio corpo, invisibilizando sua anatomia e seus processos fisiológicos particulares.

\section{A anatomia feminina na arte - Lise Lobato e Jamie McCartney}

Apesar da especificidade do contexto de Nge Lay, o tema da anatomia genital feminina percorre a arte em diversos trabalhos de artistas ao redor do mundo. A artista paraense Lise Lobato expôs uma de suas obras no Espaço Cultural das Onze Janelas no eixo "Sagrado Feminino" da exposição "Dilemas 2019" em Belém do Pará. Em seu trabalho escolhido pela curadoria de John Fletcher, pequenos objetos feitos de tecido, linha e acrilon foram fixados lado a lado.

Figura 4 - Instalação de Lise Lobato. Foto da Bienal de Mato Grosso, 2004.

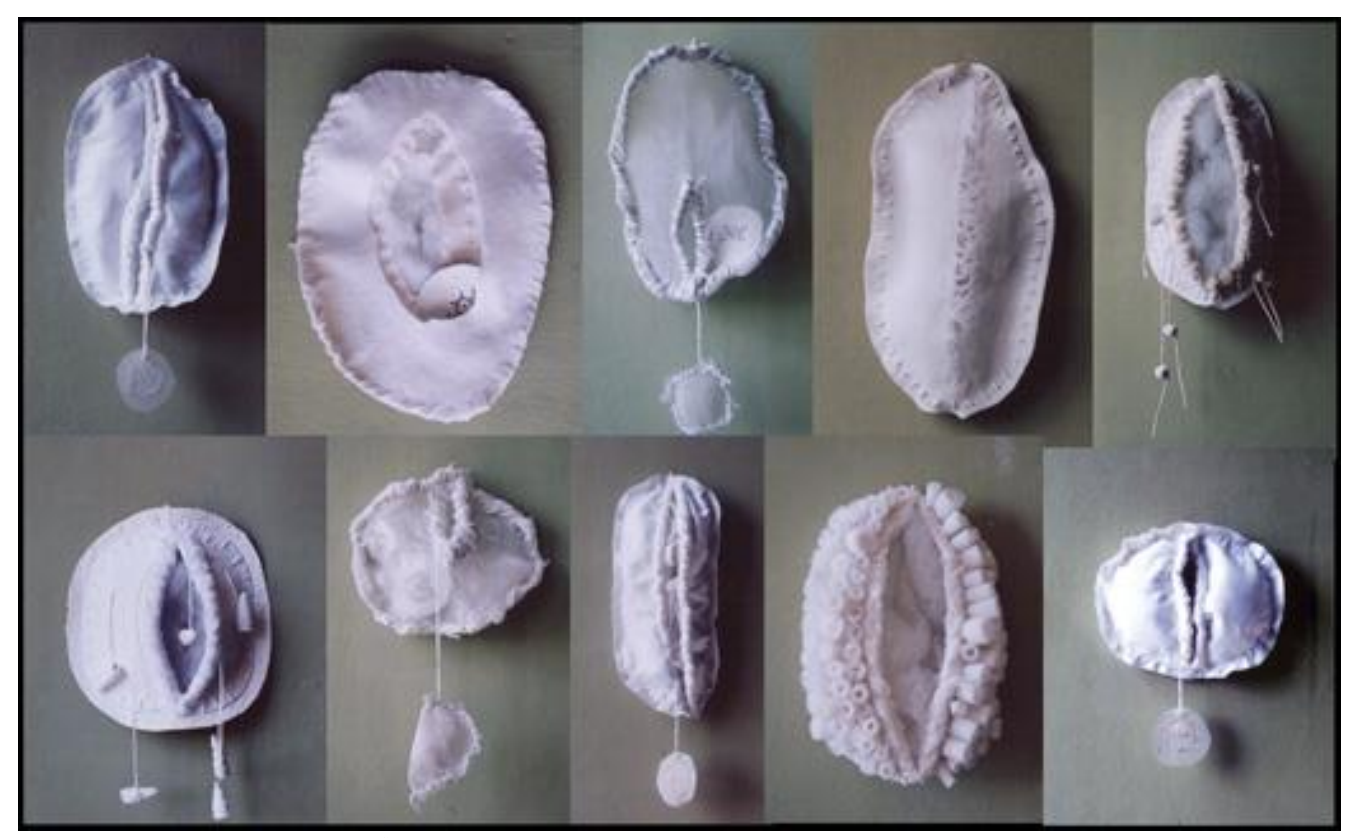

Fonte: Lise Lobato, [s.d.]. 
Quando tive a oportunidade de visitar a exposição, seu trabalho me remeteu a diferentes formatos de vulvas. Lobato conta, em diálogo feito em busca de mais detalhes do processo artístico da obra, que sua intenção inicial não tinha referencial à anatomia feminina. Na realidade, sua inspiração foram os sítios arqueológicos paraenses da Ilha do Marajó, local onde nasceu e reside. O trabalho se iniciou com a proposta de mostrar os buracos feitos por arqueólogos na terra na procura de artefatos de cerâmica indígenas. Lobato relata que durante o processo das mais de 60 peças, elas foram tomando formato de vulvas, e que o público quando se deparava com a instalação tinha esta interpretação. O título da exposição "O que tu guardas", apesar de ser uma referência à terra indígena do Marajó, também deixava aberta a possibilidade de leitura da intimidade feminina como compreensão, sendo inclusive mais frequente do que a ideia originária proposta. Para a autora tudo está relacionado: a vulva e a mãe terra, ambas como geradoras de vida. Ela ainda acrescenta: "uma obra é sempre uma obra aberta, você aceita a forma de como as pessoas as veem ${ }^{5 \prime}$.

A partir da interpretação dada por uma perspectiva feminista, o trabalho de Lobato pode ser visto como importante na narrativa para a naturalização dos diversos formatos de vulvas. Com a pressão estética cada vez mais forte sobre as mulheres, é exigido de seus corpos um padrão cada vez mais restrito e específico. Para Creighton e Liao (2019) poucas pessoas podem escapar da pressão das normas da aparência, mas as pesquisas mostram consistentemente que a maioria das mulheres está insatisfeita ou estressada pelos aspectos de sua aparência física, de forma que, na sociedade contemporânea, a insatisfação com o corpo tem caminhado junto com o fato de ser mulher. Nascimento, Próchno e Silva (2012) observam que, de forma contraditória, quanto mais parece que há um avanço na autonomia individual das mulheres, mais há exigência aos modelos sociais de corpo. Paralelamente ao desenvolvimento dos movimentos feministas, caminha a intensificação de pressões sociais de normas corporais. Se por um lado havia os ganhos no sentido da liberação do corpo feminino, para seu exercício pleno de sua sexualidade e de sua ocupação em setores da esfera pública, pelo outro a mídia já se impunha na delimitação de ações e práticas femininas, principalmente quando o assunto

5 Entrevista online cedida em maio de 2020. 
é estético. Goldenberg (2005) defende que vivemos em um "equilíbrio de antagonismos": um dos momentos de maior independência e liberdade femininas é também aquele em que um alto grau de controle em relação ao corpo e à aparência se impõe à mulher brasileira.

Com a pressão estética do mercado de consumo, as partes do corpo feminino foram sendo padronizadas, desnaturalizando corpos que não se encaixavam nas normas dos comerciais circulados pela grande mídia. Esta imposição chegou também à genitália da mulher, colocando imposições sobre o formato de sua vulva. A fim de retardar o avanço na quantidade de cirurgias plásticas íntimas trabalhos como o do artista do britânico Jamie McCartney surgiram. The Great Wall Of Vagina (em clara referência à Grande Muralha da China) traz painéis feito de moldes de vulvas de diversas mulheres ao redor do mundo. Ao todo, são 400 voluntárias, de 18 a 76 anos de idade, formando nove metros de painéis. $\mathrm{O}$ artista diz ter a intenção de educar as pessoas sobre como mulheres normais realmente se parecem, pois acredita que por conta do número de imagens pornográficas que se tem acesso hoje em dia de corpos femininos a aparência da vulva se tornou uma fonte de ansiedade para muitas mulheres. Com isso, McCartney espera que através de sua obra o público perceba que vulvas são tão diversas quanto rostos, e que o impacto de seu trabalho ajude a diminuir o aumento exponencial que as cirurgias plásticas íntimas têm tido nos últimos anos (Changing Female Body Image Through Art, s.d.). 
Figura 5 - Painel 1 da obra The Great Wall of Vagina de Jamie Mccartney, 2008.

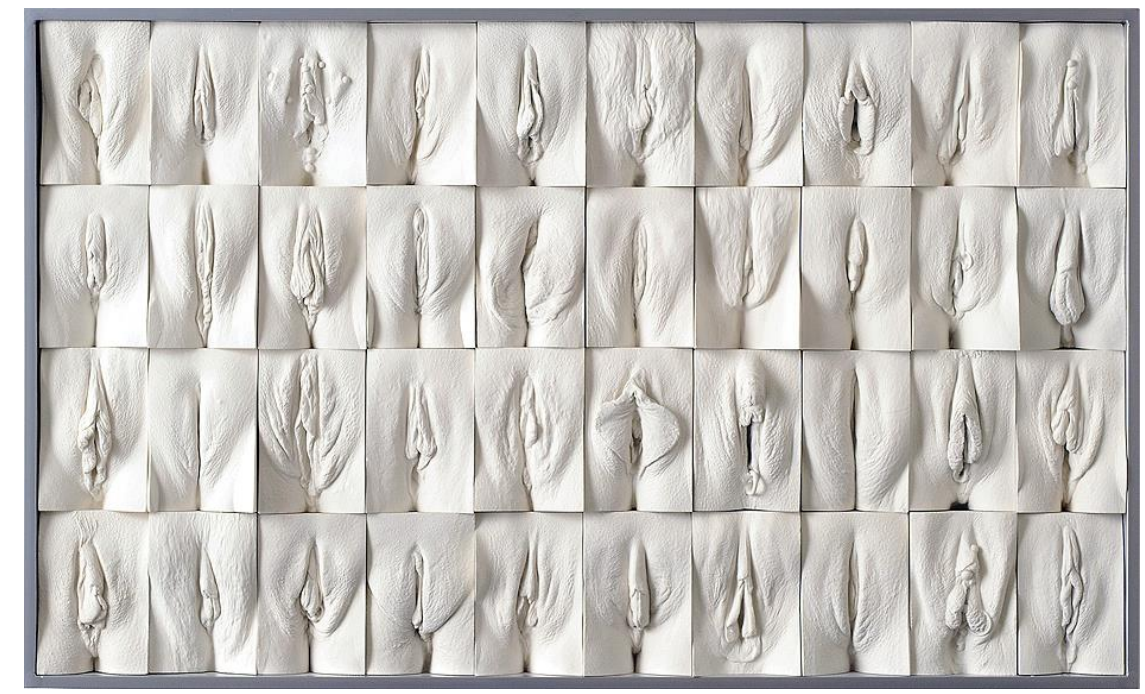

Fonte: "Changing Female Body Image Through Art", [s.d.]..

Como apontado pela obra The Great Wall of Vagina, diante do padrão de corpos imposto, houve uma desnaturalização das formas que não correspondiam ao colocado pela mídia para consumo, induzindo a um descontentamento das mulheres com sua realidade. Assim, há uma necessidade culturalmente fabricada para a cirurgia plástica, produzida como justificativa de um consumo de corpos feita por um sistema de regulação da feminilidade e do que significa ser mulher. O gasto emocional e econômico exigido pela indústria de beleza sobre as mulheres não terá fim até que as mulheres se reeduquem sobre sua própria anatomia.

\section{As cirurgias plásticas íntimas e a padronização dos corpos - Hannah Wilke e Suzanna Scott}

No Brasil, a indústria de cirurgias plásticas é famosa mundialmente pela sua grande procura pelas novas pacientes. As cirurgias plásticas íntimas, especificamente, têm se tornado moda recentemente entre as brasileiras. Vieira-Baptista, Lima-Silva e Beires (2015) questionam o alto número de cirurgias íntimas que vem sendo realizadas. Os autores apontam o modelo da "perfeição genital" feminina da contemporaneidade longe do L'Origine du Monde (Fig.6) de Gustave Courbet, e sim, mais próxima de uma genitália pré-púbere. Descrevem que a vulva desejada possui "pouco ou nenhum pelo, pequenos 
lábios recobertos pelos grandes, preferencialmente com simetria perfeita" (VieiraBaptista, Lima-Silva e Beires, 2015, p.393). Para os autores essa idealização da vulva perfeita é fruto de uma exposição a imagens constantemente manipuladas, e criticam a escolha pela intervenção cirúrgica de algumas mulheres e da aprovação de alguns cirurgiões, como uma forma de tentar corrigir a natureza.

Figura 6 - L'Origine du Monde de Gustave Courbet, 1866. Óleo sobre tela. $46 \times 55 \mathrm{~cm}$.

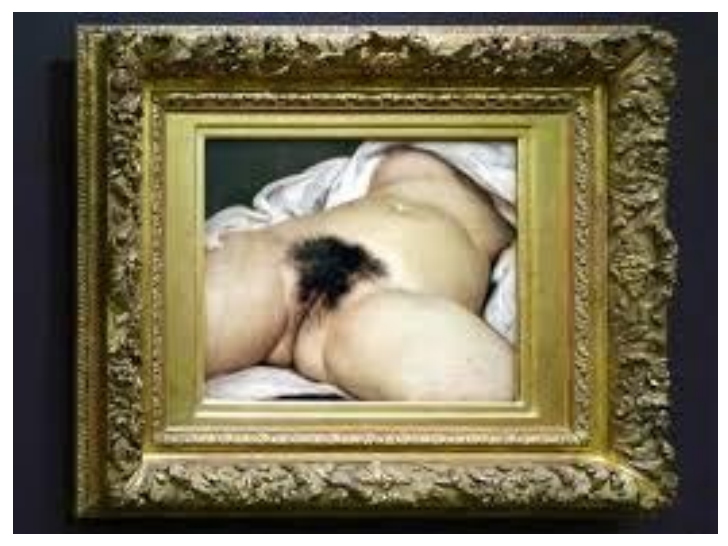

Fonte: Gustave Courbet - The Origin of the World, [s.d.].

Em um estudo desenvolvido por Silva, Paiva e Costa (2017), se observou uma maior frequência de discursos favoráveis ao "embelezamento íntimo", associados mais aos argumentos sobre "autoestima" e saúde da mulher e menos à vaidade. Segundo esses discursos, haveria uma relação direta entre saúde da mulher e embelezamento da região íntima e aparência da genitália. Porém, para o médico cirurgião português VieiraBaptista (2014), os médicos especialistas nesse tipo de procedimento fazem afirmações sem qualquer suporte científico e garantem resultados improváveis. Ainda, o autor acredita que em grande quantidade dos casos primeiramente cria-se a necessidade, inventa-se a doença ou defeito, e depois promove-se a sua cura, explorando fraquezas individuais prometendo melhoras incertas na autoestima, na função sexual, ou na vida matrimonial, por exemplo. 
Grande parte das intervenções propostas estão desaconselhadas por falta de motivos médicos para a sua realização e ausência de estudos em termos de eficácia e segurança. Não há consenso em termos da linguagem usada para denominar as diferentes intervenções. Intervém-se sobre o «ponto G», mesmo que a ciência não tenha provado a sua existência! Uma irrealista melhoria da função sexual (diminuição da dor, aumento da libido, aumento do prazer) são anunciados na maior parte dos casos, sem que de tal haja evidência científica. (VIEIRA-BAPTISTA, 2014, p. 223).

Schimitt (2014), em sua pesquisa sobre a conformação de um padrão estético de genitália feminina através de cirurgias plásticas, demonstra por meio de revisão de artigos médicos sobre a hipertrofia dos lábios menores da vulva, de que não há referência de problemas de ordem fisiológica. Os autores também comentam da existência de um enorme espectro de variação de tamanhos, cores e formas das genitálias, ainda assim Schimitt nota que há uma forte tendência a estigmatização de genitálias assimétricas, volumosas e de coloração mais escura (SCHIMITT, 2014). Sobre o processo pré-cirúrgico a autora discorre:

\begin{abstract}
Alguns autores defendem que, por se tratar de cirurgias que se baseiam em um padrão estético subjetivo, é necessário um tratamento mais individualizado, que leve em consideração as particularidades anatômicas e fisiológicas de cada paciente. Assim, afirmam que, em uma mesma paciente, dificilmente é encontrada uma simetria dos pequenos lábios, sendo necessário que o procedimento seja adaptado para as especificidades de cada caso. (SCHIMITT, 2014, p. 51).
\end{abstract}

Corroborando com o trabalho de Schimitt (2014), Andrikopoulou et al. (2013) encontraram uma escassez de informações sobre qual seria a anatomia "correta" da vulva. A autora consultou 59 livros entre anatomia e ginecologia especializada, e ainda assim conclui não haver dados suficientes para definir os tamanhos anatômicos da genitália feminina. Andrikopoulou argumenta:

Quando uma mulher saudável expressa preocupações sobre sua vulva, a resposta do médico deve ser informada pelo conhecimento clínico. As informações da morfologia vulvar são escassas e imprecisas nos livros médicos. A falta geral de recursos profissionais significa que os médicos podem, consciente ou inconscientemente, confiar em experiências pessoais e na cultura popular para formar suas opiniões, assim como seus pacientes. (ANDRIKOPOULOU et al., 2013, p. 648, tradução minha).

Em contraste às poucas referências científicas da anatomia feminina, há uma enorme quantidade de imagens que proliferam dia a dia nas mídias de massa compondo os ideais de mulheres esperados e almejados. Porém, é improvável que essas imagens, que podem ter sido alteradas digitalmente, sejam representativas do que é típico para as mulheres. 
Mesmo assim, elas podem exercer influência poderosa na autoimagem de uma mulher (Andrikopoulou et al., 2013).

A referência de obras de artistas mulheres que trabalham com temáticas feministas é uma contra proposta a estas imagens padronizadas que têm grande circulação. A artista estadunidense Hanna Wilke dedicou grande parte da sua obra a questões de feminismo, sexualidade e feminilidade. Através de uma repetição de esculturas em variados tamanhos, cores e formas, Wilke invoca no observador o imaginário da vulva em sua diversidade. Ela foi uma das primeiras artistas a usar imagens vaginais em seu trabalho com o objetivo de se envolver diretamente com questões feministas. Durante o final da década de 1950 até o início da década de 1970, Wilke trabalhou na criação de um tipo de iconografia feminina baseada no corpo, construindo formas abstratas e orgânicas que se assemelhavam à genitália feminina (GUGGENHEIM MUSEUM, s.d.). Alguns exemplares desestabilizam a forma da vulva a tal ponto que eles funcionam em um nível puramente figurativo. A artista exibia essas formas no chão ou na parede de uma maneira altamente organizada e repetitiva que remetia ao minimalismo (WILLIAMS, 2019).

A obra de Wilke no movimento deliberado e repetido sustenta cada forma atestando uma presença física. A dobradura é palpável em inúmeras esculturas dos anos 70 e 80, com materiais que variam do bronze ao chiclete. Abstratas e inconfundivelmente yônicas, as esculturas de Wilke não são ilustrações literais da vulva, mas evocações de abertura e vulnerabilidade, profundezas ocultas e intimidade. Trabalhando desde a década de 1960 até sua morte em 1993, Wilke buscou uma linguagem visual que pudesse falar sobre o que significa ser uma artista feminina - viver, amar, sofrer e desejar dentro do corpo de uma mulher (MARCINIAK, 2018, online, tradução minha). 
Figura 7 - Esculturas produzidas por Hannah Wilke entre 1960 e 1980. Materiais e dimensões variadas.

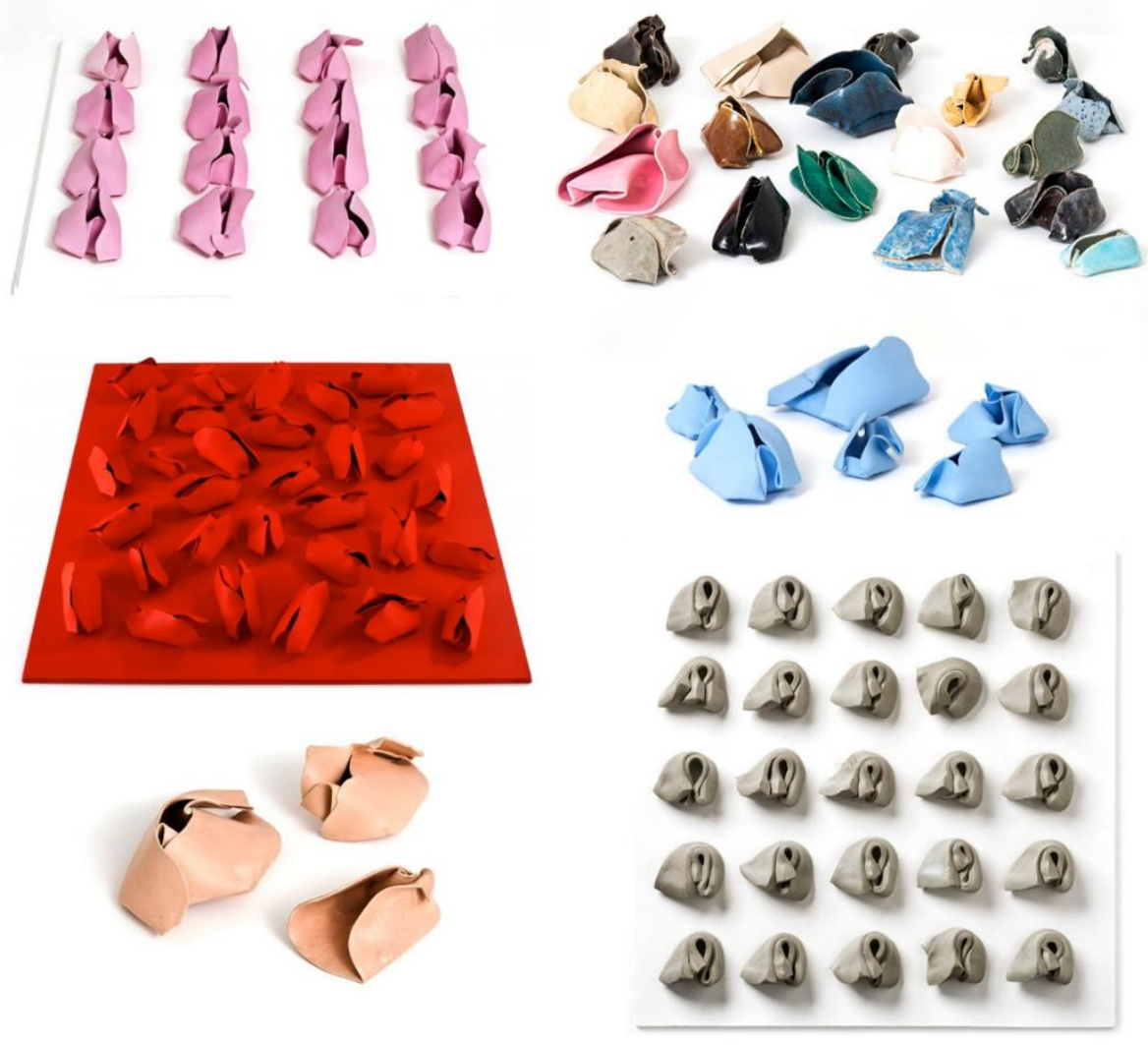

Fonte: The Art Of Hannah Wilke, [s.d.].

A obra de Wilke democratiza a percepção e a imagem da vulva, trabalhando com a sua subjetividade. De maneira não anatômica a artista nos remete à anatomia diversa dos corpos. Também neste sentido, o trabalho de Suzanna Scott nos faz enxergar a vulva de diferentes formas através de um objeto utilizado rotineiramente: porta-níqueis. A obra Coin Cunts (Fig.8) de Scott remete não só aos corpos das mulheres ao redor do mundo, como também faz associação da necessidade de mulheres terem maior autonomia econômica.

Para Scott (2015), a obra surge como contra resposta às correntes misóginas e racistas nos Estados Unidos, representando um símbolo visual de empoderamento e igualdade para todas as pessoas com vulva. A artista declara: "Ao expor o interior misterioso de um 
objeto onipresente, acho que cada porta-níquel é distinto, assim como todo ser humano é único" (SCOTT, 2015, online).

Figura 8: A obra "Coin Cunts" de Suzanna Scott, 2015. Instalação.

Dimensões variadas.

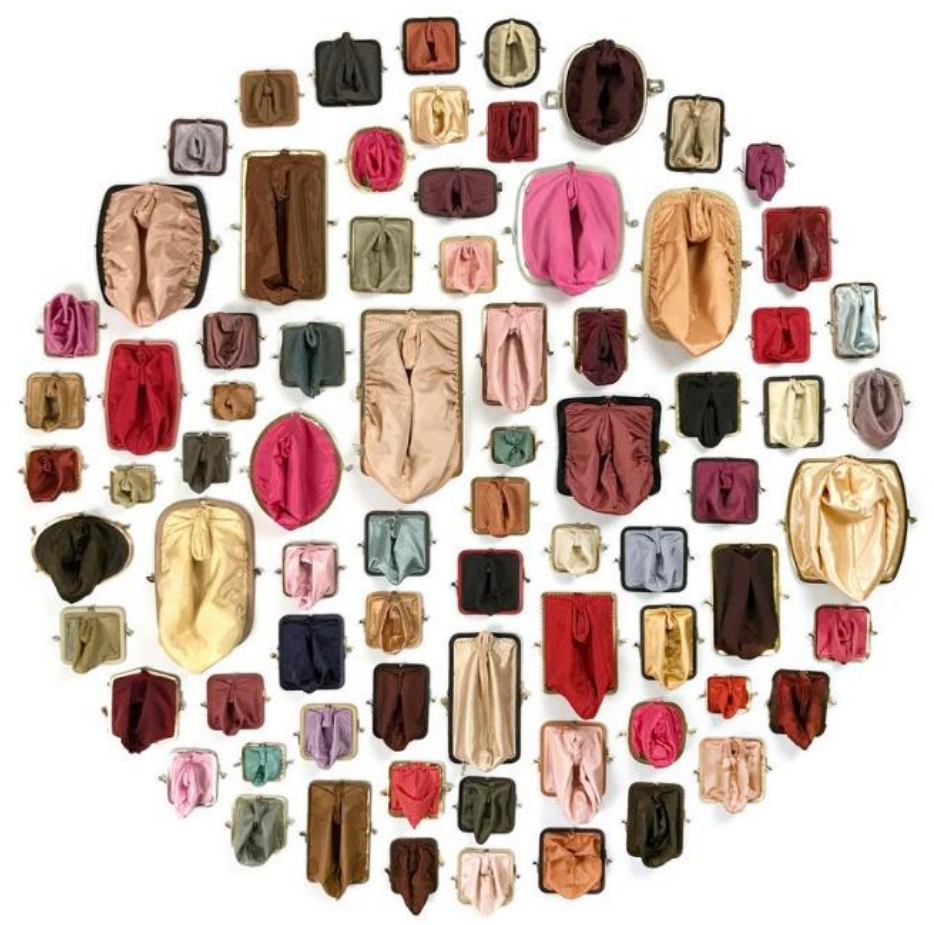

Fonte: SCOTT, 2015.

Obras como a de Wilke e Scott ajudam a desmitificar o modelo de vulva ideal, aumentando o espectro do imaginário social sobre o que pode ser considerado normalidade biológica e também o que deve ser visto como a beleza única de cada corpo. Na contramão desse discurso, Schimitt (2014) demonstra como há uma confluência entre padrões estéticos e padrões diagnósticos, havendo uma patologização das hipertrofias genitais, ou seja, variações anatômicas regulares em que haveria um tratamento recomendado através da cirurgia plástica.

Imagens de "antes e depois" ilustram nitidamente um padrão bastante marcado que fica evidente através da uniformização estética das genitálias que sofreram tais procedimentos. Nelas podemos observar uma homogeneidade estética e uma profunda diminuição do volume aparente que nos leva a crer que, a 
despeito do que alguns médicos afirmam, há sim um padrão estético almejado tanto por cirurgiões, quanto pelas pacientes. (SCHIMITT, 2014, p. 53).

A autora reitera que a história da medicalização da mulher está permeada por moralidades sexistas, em que a ninfomania e a histeria, por exemplo, eram diagnosticadas a partir de preceitos machistas sobre o comportamento da mulher. E que muitas vezes o tratamento consistia em "atacar" diretamente a vulva da mulher e seu sistema reprodutor como diagnóstico. Schimitt (2014) conclui "tudo que ali não estivesse a serviço da reprodução caracterizaria anormalidade e patologia" (SCHIMITT, 2014, p. 26). A partir dessas convenções, práticas como a cliteridectomias ${ }^{6}$ e ovariotomias ${ }^{7}$ foram institucionalizadas. Assim, doenças sem comprovação fisiológica foram diagnósticas inúmeras vezes nos corpos das mulheres, e, paulatinamente, a falta de beleza, vista anteriormente apenas como defeito, foi também sendo tratada como patologia (SCHIMITT, 2014).

Creighton e Liao (2019) questionam como que é possível que existam procedimentos assegurados pela lei para alterar a estrutura e a aparência da genitália feminina sem a prerrogativa de uma preocupação médica. As autoras argumentam: "sabemos que não houve um surto de crescimento labial em todo o mundo" (CREIGHTON e LIAO, 2019, p. 4, tradução minha). A provocação feita através da constatação óbvia - de que a anatomia feminina não se transformou radicalmente nas últimas décadas a ponto de justificar o aumento dos procedimentos estéticos íntimos - serve para compreendermos a ausência de pretexto biológica para tais práticas. Desta forma, a invenção e o aumento da procura por cirurgias íntimas estéticas apenas se fundamentam pela maneira como percebemos e lidamos com nossa anatomia de maneira cultural.

\section{A colonização dos corpos - Willie Bester}

Assim como outras características sexuais, os simbolismos e significados acerca da aparência da genitália são culturalmente construídos. As fronteiras binárias bem

6 Procedimento de remoção do prepúcio do clítoris.

7 Extração cirúrgica do ovário, ou de cistos do ovário. 
demarcadas difundidas historicamente pela medicina, fazem com que aspectos associados ao sexo oposto sejam rechaçados. Enquanto a genitália masculina é caracterizada como voluptuosa e com grande valorização de seu tamanho, a feminina deve ser discreta, pequena, quase imperceptível (CREIGHTON e LIAO, 2019). Com isso, as vulvas consideradas volumosas pelo olhar médico tendem a ser patologizadas com pretextos mais culturais do que científicos.

A medicina europeia, caracteristicamente masculina e branca, e com grande influência no ocidente devido ao processo de colonização, patologizava o que the saia de sua referência. Assim, corpos não-brancos, de características anatômicas distintas do modelo europeu, foram e ainda são tratados como fora da normalidade, alimentando a indústria de beleza e, consequentemente, de cirurgias plásticas, através do sentimento de inadequação.

Nesse sentido, há um padrão hegemônico que se reafirma através da mídia e da realização dos procedimentos estéticos íntimos. A vulva ideal propagada tanto na mídia quanto na medicina não foi ao acaso: a vulva perfeita é aquela próxima aos modelos de beleza colonialistas, enquanto as demais são renegadas de sua beleza estética. Sendo assim, vulvas não-brancas são pouco ou não são representadas nos meios de comunicação ou nos livros de anatomia.

Saartjie Baartman, mulher negra originária dos povos Khoi Khoi no vale do rio Gamtoos (atual África do Sul), causava espanto na Europa no século XIX sendo exibida em circos por conta de suas "peculiaridades anatômicas". Saartjie, assim como demais mulheres dos povos Khoi Khoi e Khoi-San, chamou atenção de cientistas ocidentais por possuírem os "pequenos lábios" vaginais muito maiores do que os ditos "grandes lábios" 8 . Em sua cultura de origem o relativo excesso de pele pendendo da vulva era algo considerado extremamente belo e símbolo de poder, sendo manipulada com o objetivo específico de alongá-la. Porém, na Europa a peculiaridade de Baartman foi associada a inúmeras

8 Sobre a denominação "pequenos e grandes lábios" há um movimento levantado por feministas e ginecologistas pedindo a substituição do termo para "lábios internos e externos", a fim de evitar o incomodo em mulheres que possuem os lábios internos maiores que os externos. 
categorias depreciativas que a relacionavam a uma natureza essencialmente sexual e animalesca (SCHIMITT, 2014).

Figura 9 - Impressão francesa do século XIX La Belle Hottentot de Saartjie Baartman, 1815.

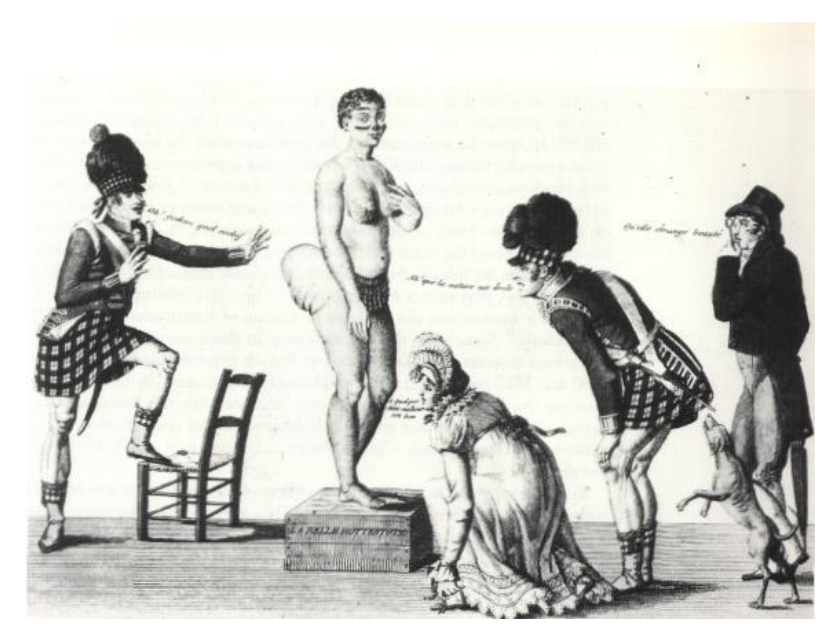

Fonte: "print; satirical print", [s.d.].

Como khoisan, seu corpo era diferente do corpo de uma mulher branca. Pelo formato dos quadris, seios e genitália, o olhar europeu tratava suas formas de maneira extremamente sexualizada. Mais abrangente, pode-se dizer que, à época, os khoisan eram considerados o povo "menos desenvolvido", o mais "primitivo" do mundo, pelo pensamento eurocêntrico e sua teoria de superioridade racial, e usavam tais ideias como estratégia de dominação. (TORNICH, 2019, p. 101).

A trajetória de Sarah "Saartjie" Baartman se tornou um símbolo do racismo legitimado pela ciência, com sua imagem sendo pautada na luta das mulheres negras por dignidade e igualdade. Em 2020 o artista sul-africano Willie Bester doou à Universidade de Cape Town uma escultura inspirada em Baartman, feita com objetos de metal reciclado. A obra causou grande polêmica pelas feministas negras que apontaram para a colonialidade da obra pelo fato de Saartjie estar representada nua, como nas gravuras europeias. Em protesto, estudantes negras cobriram a escultura, a "vestindo". A indignação demonstrada com a obra pelas feministas é justificada, considerando sua trajetória desumana pelo continente europeu em que era tratada como objeto de estudo 
como um artefato, com decisões feitas sobre seu corpo contra sua vontade (CLOETE, 2018).

Figura 10 - A escultura Sarah Baartman de Willie Bester. Metal reciclado, $210 \mathrm{~cm}$, 2000. Universidade de Cape Town.

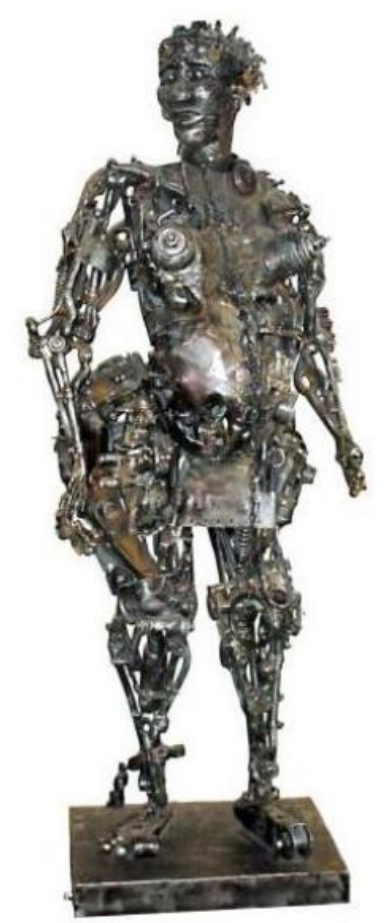

Fonte: CLOETE, 2018.

Após o falecimento de Saaartjie, foi um longo e tardio processo para o retorno dos restos mortais para a sua terra natal, até então expostos no Musée de l'Homme em Paris. Segundo relatos, Baartman em vida teria se recusado a servir de estudo anatômico para George Cuvier, porém, o naturalista francês ficou encarregado do dessecamento de Sarah para pesquisas antropológicas após sua morte mesmo sem sua autorização. Cuvier descreveu as "anomalias" da genitália de Baartman, denominando a hipertrofia dos pequenos lábios genitais como "cortina de pudor". O que o cientista não imaginava, é que a hipertrofia diagnosticada por ele era fruto de um hábito cultural, e não de uma característica congênita. Como recorrente na história antropológica, o olhar colonial limitou a leitura do fenômeno estudado (SCHIMITT, 2014). 
Acreditava-se que as características da vulva das mulheres eram relacionadas com seu comportamento, colocando a vulva branca e menor como evidência de recato, ilustrando pureza, ingenuidade e feminilidade. Essa anatomia específica do corpo colonialista foi defendida pela medicina como o padrão de normalidade. Enquanto as mulheres negras, que apresentavam vulvas maiores, eram consideradas selvagens e libidinosas, sendo negada a sua humanidade. Assim, se aprimorava a hierarquização racial que não atingia somente os costumes, mas também os corpos (SCHIMITT, 2014).

Infelizmente, podemos perceber que, ainda hoje, o tamanho dos lábios vaginais está estreitamente relacionado a concepções anatômicas simplistas e até mesmo moralizantes, o que contribui para reiteração de padrões estéticos dicotômicos e para um desconforto constante daquelas que fogem à norma estética estabelecida. (SCHIMITT, 2014, p. 10).

A descrição anatômica colonial segue até hoje nos livros de anatomia e ginecologia, sendo amparada pela ciência que se julga neutra, sem perceber as raízes herdadas do domínio europeu que se manifestam ainda hoje. A arte, por sua vez, busca desmitificar tais conceitos biologizantes. Desconstrói os padrões dos corpos impostos pela medicina e pela grande mídia, assim como denuncia a relação arraigada historicamente de que comportamentos femininos seriam justificados pela anatomia de suas vulvas.

Nge Lay buscou expressar em seu trabalho toda a potência feminina a partir da figura da vulva. Lay argumenta que a sua obra representa a maternidade, além de "valores culturais, a beleza da natureza, e o orgulho saudável de um país". Como citado anteriormente, além da vulva pendurada, há também um vídeo posicionado ao lado da descrição da obra, e um colchão no chão, que é colocado atrás da vulva. O colchão, também costurado com tecidos semelhantes aos da vulva, pode ser utilizado por aqueles que desejam deitar-se depois de atravessarem a obra de Nge Lay. A artista diz que queria que as pessoas se sentissem à vontade para descansar após a travessia, caso quisessem. Fazendo alusão ao cansaço que seria "renascer" já na idade adulta.

Ao lado de sua obra, Nge Lay expõe um vídeo, no qual mostra mulheres de diferentes faixas etárias sentadas em roda sobre seu trabalho. Naquele momento, por não estar pendurado, não serve como um portal, mas, sim, como um local de repouso e de conversa. As mulheres convidadas discutem o que significa ser mulher em Mianmar, e como o machismo atrapalha ou até mesmo inviabiliza suas escolhas pessoais. Elas 
expõem as dificuldades em optar pelos cursos que gostariam, em exercer sua profissão de escolha ou ter a liberdade para poderem permanecer sem casar. Assim, com as dimensões políticas e sociológicas evidentes no seu trabalho, Lay afirma que o debate de gênero se faz necessário em sua realidade:

Na sociedade atual de Mianmar, a discriminação sexual em nossa vida cotidiana e no ambiente de trabalho não é tão forte quanto antes. No entanto, devido a convenções profundamente arraigadas, bem como a desequilíbrios econômicos e políticos, o papel das mulheres ainda não foi reconhecido. (Nge Lay, em entrevista para a revista digital Living Asean, tradução minha).

Podemos relacionar o trabalho de Nge Lay com o ensaio de Gayatri Spivak (2010) "Pode o subalterno falar?", no qual aborda a necessidade da descolonização das narrativas de poder, colocando a mulher não-branca como um sujeito sem voz, que não tem espaço para se posicionar dentro do cenário político e social. Lay tenta romper com essa estrutura colonial em que seu trabalho é exposto demonstrando a necessidade de se falar do corpo da mulher em outras perspectivas que não a de subordinada, mas de empoderada de seu corpo. O vídeo complementa a obra, em que a artista deixa claro a discussão que pretende fazer surgir a partir de seu trabalho.

Acredito que a maior relevância da obra de Nge Lay é a visibilidade que a artista possibilita dessas vivências, lançando luz a discussões necessárias que rompem com o patriarcado birmanês. Experiências e reflexões que podem ser trazidas para diferentes contextos tanto como para o restante do oriente quanto para o ocidente. No momento em que uma vulva é exposta em um espaço de poder institucionalizado como um museu, se ganha novas perspectivas da anatomia feminina. Passando pela obra de Lay não é possível ignorá-la. Para além da porta construída pela vulva em seu entorno, se abre uma porta para a discussão e valorização feminista.

\section{Valorização feminista e arte contemporânea - Zoe Leonard}

A historiadora Tvardovskas (2015) defende que as práticas feministas da arte contemporânea como forma de autotransformação, desconstrução de modelos políticos autoritários e de representações misóginas sobre os corpos femininos. A autora acredita que através dessas práticas é possível ampliar o olhar para as resistências micropolíticas, 
no plano das subjetividades que aspiram também uma transformação cultural, social e política mais copiosa.

São muitas as artistas hoje ao redor do mundo que se utilizam de diferentes mídias, das artes visuais, do teatro, da música, do cinema ou da literatura para discutir a constituição de subjetividades femininas, renovando o imaginário social e desconstruindo estereótipos e crenças culturais sobre as mulheres. A arte se compõe, assim, como um dos lugares do social em que são geradas múltiplas resistências e onde se tensionam complexamente os enunciados normativos. (TVARDOVSKAS, 2015, p. 3).

A artista estadunidense Zoe Leonard questiona a normatividade masculina e branca de pintores dentro dos museus com o trabalho exposto na Documenta IX ${ }^{9}$. Utilizando da própria coleção do museu, Leonard alternou pinturas alemãs do século XVIII com fotografias preto e branca de vulvas. A artista optou por retirar os retratos masculinos, as pinturas históricas e as paisagens da galeria, deixando apenas as telas que haviam mulheres retratadas. As 19 obras removidas foram substituídas pelas fotografias da genitália de suas amigas. Suas imagens faziam referência à obra L'Origine $d u$ Monde (Fig.6) de Gustave Courbet, porém com o diferencial de que a mulher retratada não estava passiva como no quadro do pintor francês, e, sim, com uma mão em sua virilha em referência à masturbação. Com isso, Leonard critica o monopólio do "olhar masculino" da pintura clássica, no qual coloca o sexo e o poder reprodutivo das mulheres em uma narrativa tradicional, contida e burguesa. A resposta da artista à sua própria crítica é a transformação do significado da coleção existente: o que antes exaltava o estilo de vida burguês tradicional, exalta o prazer feminino renegado na época (SMITH, 1992).

Sua instalação de fotografias em preto e branco de vulva para a Documenta IX (1992), em sete salas de pintura da Neue Galerie em Kassel, deu um golpe no museu como o "naturalizamos": patriarcal, branco, heterossexual e, portanto, tendencioso em seu universalismo. (DURAND, 2017, online, tradução minha).

9 A documenta é uma exposição de arte contemporânea que ocorre a cada cinco anos em Kassel, Alemanha. 
Figura 11 - Zoe Leonard, Sem título (Gravuras da instalação Documenta IX), 1992. Coleção Flamengo Community. Instalação na Neue Galerie, Documenta IX, Kassel, composta por 19 fotografias em preto e branco afixadas nas paredes das galerias. Fotografia por: Dirk Pauwels. Cortesia de S.M.A.K., Stedelijk Museum voor Actuele Kunst, Gent.
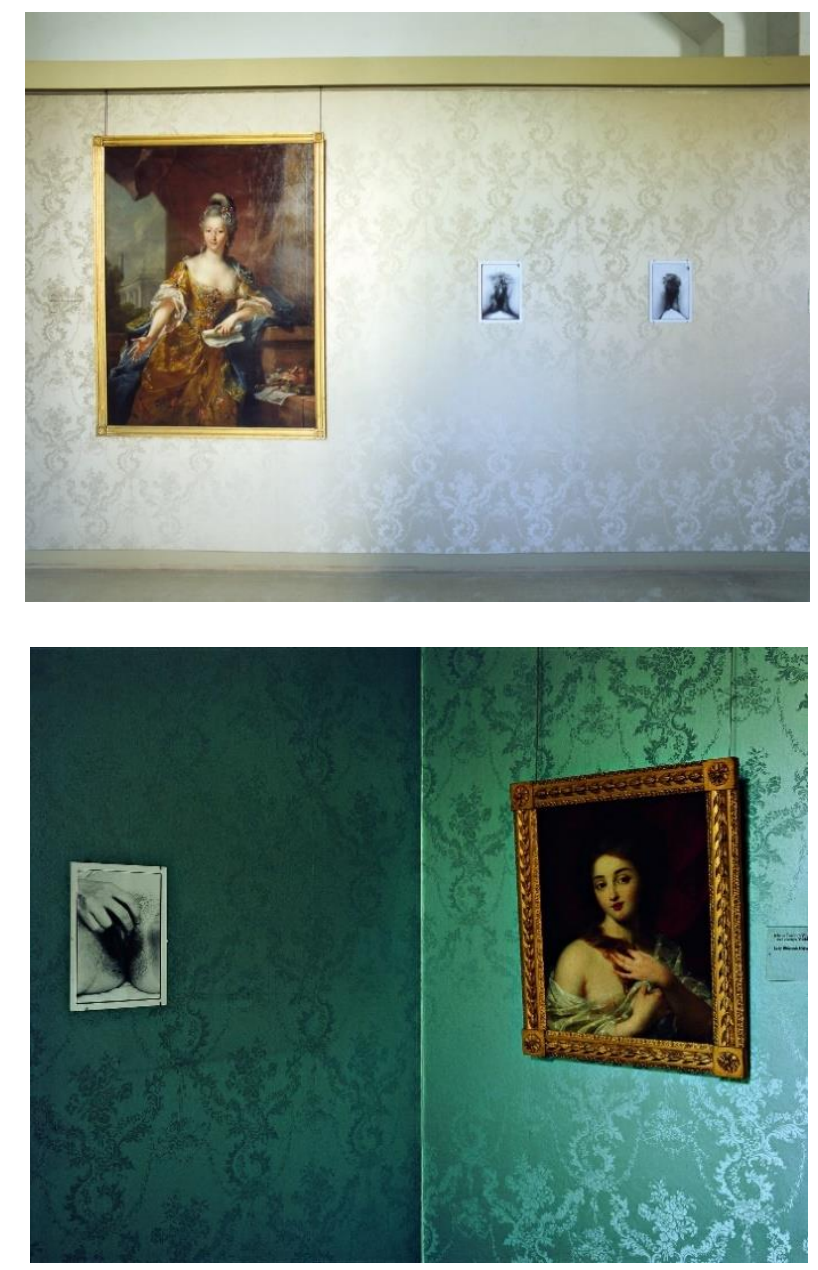

Fonte: DURAND, 2017.

Embora as imagens produzidas por Leonard funcionassem também como potenciais de desejo masculino direto, ela as apresentava como exemplos de vezes que mulheres sentiram prazer pelas suas próprias mãos. A artista declaradamente lésbica fala sobre uma das intenções com o trabalho: "Eu não estava interessado em reexaminar o olhar masculino; eu queria entender o meu próprio olhar" (LEONARD apud CHAVE, 2010, p. 25). Tvardovskas (2015) argumenta que por meio da experiência feminina são confrontados os enunciados binários e as práticas sexuais falocêntricas, sendo pensadas 
novas configurações dos prazeres e uma multiplicidade de práticas e saberes produzidos pelos corpos.

\begin{abstract}
Além de rejeitar os binarismos, as feministas politizaram o corpo, denunciando como o poder patriarcal trabalhava por meio de normas culturais sobre o feminino. Em outras palavras, suas reflexões mostraram que o poder afeta diretamente os corpos, convergindo para uma compreensão de que as questões da subjetividade são inseparáveis das questões do corpo. (TVARDOVSKAS, 2015, p. 14).
\end{abstract}

Tvardovskas (2015) acredita ser cada vez mais urgente um conhecimento situado que deixe de lado os pseudo-universalismos. É importante para a arte, e para o mundo, que as propostas sejam múltiplas e fragmentadas, que sejam abrangentes na diversidade de experiências culturais e históricas para além do sujeito masculino, branco e ocidental. Construindo, assim, um novo imaginário social e cultural das realidades que ainda não foram contadas, ou expostas.

\title{
Considerações Finais
}

O patriarcado agiu e ainda age de diferentes formas ao redor do mundo, porém o incômodo causado pela exposição da genitália feminina parece possível de ser identificada em diversas realidades e contextos históricos. A vulva é invisibilizada frequentemente em condições em que a autonomia e a sexualidade da mulher é reprimida e controlada socialmente. Obras clamando por visibilidade como a de Nge Lay e as demais citadas neste trabalho, demonstram o apagamento histórico da fisiologia feminina, ainda presentes no cotidiano das mulheres em diversos locais do mundo.

A vulva desperta discussões e polêmicas em torno da anatomia feminina, entre representatividades e silenciamentos, a bandeira feminista pela naturalização dos corpos das mulheres na ciência, na arte e na sociedade como um todo, segue sendo levantada. Porém, há um longo caminho a ser percorrido no que tange a autonomia das mulheres sobre a sua própria vulva e quanto ter uma vulva tira a sua autonomia.

O recorte feito dos artistas abordados no presente artigo demonstra como há a necessidade de mais pesquisas que deem visibilidade para um maior número de trabalhos fora do eixo da América do Norte e Europa. Infelizmente, artistas latinoamericanos, africanos e orientais ficam frequentemente em menor evidência na arte 
contemporânea. Com isso, mesmo com o objetivo da pesquisa de trazer um maior número de artistas destas regiões, tive dificuldade em acessá-los. As duas artistas fora desse eixo (Nge Lay e Lise Lobato), e que tive como objetivo dar um maior destaque durante a pesquisa, foram casos em que tive oportunidade de ver seus trabalhos in loco. Apesar de terem sido o ponto inicial do interesse pelo estudo, os demais casos aqui expostos foram encontrados durante a pesquisa online sobre o tema. Foram acessados também outras obras abrangendo a sexualidade da mulher de artistas de diferentes localidades do mundo, porém, com o recorte bem delimitado sobre a abordagem da vulva em si, optei por não fazerem parte deste estudo especificamente.

Ainda assim, é trazendo as pautas, seja através de pesquisas, seja através da arte, que se torna possível transformar realidade das mulheres que se sentem constrangidas pelos seus corpos por conta de não estarem dentro de um padrão estético construído para excluir. Opressões ligadas ao corpo das mulheres perdem espaço conforme manifestações feministas, artísticas ou não, se espalham e ganham território político. Desta maneira, se busca vislumbrar um futuro em que corpos femininos possam ser vistos enquanto corpos potentes e dignos de liberdade e afeto, independente de seus marcadores sociais.

\section{Referências}

ANDRIKOPOULOU, Maria; MICHALA, Lina; CREIGHTON, Sarah M., LIAO Lih-Mei. The normal vulva in medical textbooks. Journal of Obstetrics and Gynaecology. Out, 2013

BEAUVOIR, Simone. O Segundo sexo - fatos e mitos; tradução de Sérgio Milliet. 4 ed. São Paulo: Difusão Européia do Livro, 1980.

CHANGING FEMALE BODY IMAGE THROUGH ART. The Great Wall of Vagina. [s.d.]. Disponível em: http://www.greatwallofvagina.co.uk/about. Acesso em: 27 de maio de 2020.

CHAVE, Anna C. "Is this good for Vulva?" - Female Genitalia in Contemporary Art. The Visible Vagina. Francis M. Naumann Fine Art, LLC. David Nolan Gallery, Inc. Nova York, janeiro de 2010. 
CLOETE, KIM. Dignifying Sarah Baartman. University of Cape Town. Set., 2018. Disponível em: https://www.news.uct.ac.za/article/-2018-09-21-dignifying-sarahbaartman. Acesso em: 12 de maio de 2020.

CREIGHTON, Sarah M., LIAO Lih-Mei. Female Genital Cosmetic Surgery: Solution to What Problem? Cambridge United Kingdom; New York, NY: Cambridge University Press, 2019

DABROWSKI, Magdalena. Stieglitz and His Artists: Matisse to O'Keeffe: the Alfred Stieglitz Collection in the Metropolitan Museum of Art. Metropolitan Museum of Art, 2011.

DROHOJOWSKA-PHILP, Hunter. Full Bloom: The Art and Life of Georgia O'Keeffe. W. W. Norton \& Company, 17 de set. de 2004.

DURAND, Jean-Marie, "Ce que le sida m'a fait" d'Elisabeth Lebovici: I'art au temps du $\mathrm{VIH}$. Les Inrockuptibles, 2017. Disponível em: $<$ https://www.lesinrocks.com/2017/08/29/arts/arts/ce-que-le-sida-ma-fait-delisabethlebovici-lart-au-temps-du-vih/>. Acesso em: 28 de maio de 2020.

GOLDENBERG, Mirian. Gênero e corpo na cultura brasileira. Psicologia Clínica, Rio De Janeiro, Vol.17, N. 2, P. 65 - 80, 2005.

GuGGenheiM. Collection Online: Hannah Wilke. [s.d.] Disponível em: https://www.guggenheim.org/artwork/artist/hannah-wilke. Acesso em: 29 de maio de 2020.

GUSTAVE COURBET - THE ORIGIN OF THE WORLD. Musée d'Orsay. [s.d.] Disponível em: <https://www.musee-orsay.fr/en/collections/works-infocus/search/commentaire/commentaire_id/the-origin-of-the-world-

3122.html?no_cache $=1>$

LISE LOBATO. Cultura Pará. [s.d.]. Disponível em: http://www.culturapara.art.br/artesplasticas/liselobato/index.htm. Acesso em: 15 de maio de 2020,

MARCINIAK, Caroline. Hannah Wilke: What It Means to Be a Woman Artist. Frieze. Out., 2018. Disponível em: https://frieze.com/article/hannah-wilke-what-it-means-bewoman-artist. Acessado em: 29 de maio de 2020.

MARTIN, Emily. A mulher no corpo: uma análise cultural da reprodução. Rio de Janeiro, Editora Garamond, 2006.

NASCIMENTO, Christiane Moura; PRÓCHNO, Caio César Souza Camargo; SILVA, Luiz Carlos Avelino da. O corpo da mulher contemporânea em revista. Fractal: Revista de Psicologia. Vol.24, N.2. Rio de Janeiro. Mai/Ago, 2012.

NGE LAY AND PANNAPHAN YODMANEE AT BANGKOK ART BIENNALE. Yavuz Gallery, 2018. Disponível em: <https://yavuzgallery.com/aquilizan-nge-lay-andpannaphan-yodmanee-at-thai-biennales/>. Acesso em: 7 de julho de 2019. 
NGE LAY'S CHECKPOINT. Yamin, 2018. Disponível em: $<$ https://www.yaminburma.com/blog/2019/4/12/nge-lays-the-checkpoint>. Acesso em: 7 de julho de 2019.

NOCHLIN, Linda. "Why Have There Been No Great Women Artists? Thirty Years After". In: ARMSTRONG, Carol; ZEGHER, Catherine (Eds.). Women Artists at the Millennium. Cambridge, MA: MIT Press, 2006. P. 21-32.

PRINT; SATIRICAL PRINT. The British Museum. Disponível em: https://www.britishmuseum.org/collection/object/P_1998-0426-7.

RANCIÈRE, Jacques. A partilha do sensível: estética e política. Tradução de Mônica Costa Netto. São Paulo: EXO Experimental org; Editora 34, 2005.

SCHIMITT, Marcelle. Sinus Pudoris - Conformação de um padrão estético de genitália feminina através de cirurgias plásticas. Instituto de Filosofia e Ciências Humanas. Departamento de Antropologia. Universidade Federal do Rio Grande do Sul. Porto Alegre, 2014.

SCOTT, Suzanna. Coin Cunts: an ongoing project featuring a varied collection of altered coin purses. Suzanna Scott. 2015. Disponível em <https://www.suzannascott.com/art/coin-cunts/view/680553/0/680554>. Acesso em: 29 de maio de 2020.

SILVA, Marcelle Jacinto da; PAIVA, Antonio Cristian Saraiva e COSTA, Irlena Maria Malheiros da. A vagina pós-orgânica: intervenções e saberes sobre o corpo feminino acerca do "embelezamento íntimo". Horizontes antropológicos. 2017, vol.23, n.47, pp.259-281.

SMITH, Roberta. Review/Art; A Small Show Within an Enormous One. The New York Times. P. 13, Jun/1992. Disponível em: <https://www.nytimes.com/1992/06/22/arts/review-art-a-small-show-within-anenormous-one.html>. Acesso em: 28 de maio de 2020.

SPIVAK, Gayatri Chakravorty. Pode o subalterno falar? 1. ed. Trad. Sandra Regina Goulart Almeida; Marcos Pereira Feitosa; André Pereira. Belo Horizonte: Editora da UFMG, 2010.

THE ART OF HANNAH WILKE. Hannah Wilke. [s.d.]. Disponível em: http://www.hannahwilke.com. Acessado em: 29 de maio de 2020.

TORNICH, Carolina de Campos. Itinerários de Willie Bester nos cenários da África do Sul e de Expografia Mundializada. Universidade de São Paulo. Programa Interunidades em Estética e História da Arte. São Paulo, 2019.

TVARDOVSKAS, Luana Saturnino. Dramatização dos corpos: arte contemporânea e crítica feminista no Brasil e na Argentina. São Paulo: Intermeios, 2015.

VIEIRA-BAPTISTA, Pedro. "Cirurgia íntima" - tempo de impor limites. Acta Obstétrica e Ginecológica Portuguesa. 8(3):223-225. 2014.

Pedro; LIMA-SILVA, Joana; BEIRES, Jorge. «Cirurgia íntima»: o que se faz e com 
que bases científicas? Acta Obstétrica e Ginecológica Portuguesa. vol.9 no.5 Coimbra dez. 2015.

WILLIAMS, Hannah. Hannah Wilke's Naked Crusade to Subvert the Patriarchy. Artsy. Jan, 2019. Disponível em <https://www.artsy.net/article/artsy-editorial-hannah-wilkesnaked-crusade-subvert-patriarchy>. Acesso em: 29 de maio de 2020.

Recebido: 14.03.2020

Aprovado: 27.06.2020 